\title{
Viabilidade Gastrointestinal Simulada de Micropartículas com Lactobacillus acidophilus Obtidas por Gelificação lônica
}

Greice Carine Raddatz (I), Mariana de Araújo Etchepare (I), Gabriela Poletto (I), Maria Fernanda da Silveira Cáceres de Menezes (I), Marina Pippi Barin (I), Thaiane Marques da Silva (I), Augusto Tasch Holkem (I), Carlos Pasqualin Cavalheiro (I), Hilda Hildebrand (I), Cristiano Ragagnin de Menezes (I)

(I) UFSM - Universidade Federal de Santa Maria (Avenida Roraima)

\section{Resumo}

A principal barreira dos microrganismos probióticos após sua ingestão é o trato gastrointestinal, onde estes devem resistir ao suco gástrico, à bile e à secreção pancreática mantendo-se viáveis para colonizar o intestino e promover seu efeito benéfico. Diversos estudos têm mostrado que os probióticos podem ser significativamente protegidos através da técnica de microencapsulação.O objetivo deste trabalho foi avaliar a viabilidade de micropartículas com Lactobacillus acidophilus obtidas por gelificação iônica frente às condições gastrointestinais simuladas.A produção das microcápsulas foi realizada através da técnica de extrusão/aspersão. Foram preparadas duas soluções: a primeira contendo $1 \%$ de alginato de sódio (ALG) e a segunda contendo $1 \%$ de alginato de sódio + $1 \%$ de Hi-maize (prebiótico) (AHM), ambas contendo Lactobacillus acidophillus como probióticos.Para avaliar a resistência das microcápsulas frente às condições gastrointestinais, fez-se o uso de $1 \mathrm{~g}$ de micropartículas com incubação sequencial, em condições simuladas in vitro do ambiente gástrico em $\mathrm{pH}$ 1,8 , por 120 minutos. Logo, o $\mathrm{pH}$ foi alterado para 5,0 para simular as condições do ambiente intestinal, também por 120 minutos e, para finalizar a análise, o pH foi novamente alterado para 7,5 ainda simulando condições

\footnotetext{
Referência:

Greice Carine Raddatz, Mariana de Araújo Etchepare, Gabriela Poletto, Maria Fernanda da Silveira Cáceres de Menezes, Marina Pippi Barin, Thaiane Marques da Silva, Augusto Tasch Holkem, Carlos Pasqualin Cavalheiro, Hilda Hildebrand 1, Cristiano Ragagnin de Menezes. Viabilidade Gastrointestinal Simulada de Micropartículas com Lactobacillus Acidophilus Obtidas por Gelificação lônica. In: Anais do 12을 Congresso Latinoamericano de Microbiologia e Higiene de Alimentos - MICROAL 2014 [= Blucher Food Science Proceedings, num.1, vol.1]. São Paulo: Editora Blucher, 2014.

DOI $10.5151 /$ foodsci-microal-164
} 
intestinais por mais 120 minutos.Comparando as duas formulações (ALG e AHM) após o aumento do pH 1,8 para pH 5,0 e , em seguida, pH 5,0 para pH 7,5, o número de células viáveis para todos os tratamentos foi $106 \log$ UFC/g, estando dentro dos padrões exigidos para que ocorram os benefícios exercidos pelos probióticos. No final da análise obtiveram-se reduções de log de 3,67 e 3,01 para as microcápsulas ALG e AHM respectivamente quando comparadas à contagem do tempo zero, demonstrando que os tratamentos apresentaram diferenças significativas entre si. O tratamento AHM apresentou a menor perda de viabilidade no decorrer da simulação do trato gastrointestinal. Estes resultados indicam que a microencapsulação de Lactobacillus acidophilus, utilizando alginato de sódio como principal material encapsulante, pode aumentar a sobrevivência celular mesmo quando submetido a condições adversas. No entanto, observa-se que a proteção pode ser significativamente melhorada se houver a adição de um prebiótico na formulação da cápsula.

Palavras-Chave: gelificação iônica, Lactobacillus acidophilus , microencapsulação, simulação gastrointestinal, viabilidade

Agência de Fomento: 